\title{
REFERENCES
}

Friedel, F. (1989). Computer in Menschenturnieren. Antwort der Redaktion. Computerschach und Spiele, No. 6, p. 7.

Fürstenberg, M.T. (1989). Computer in Menschenturnieren. Computerschach und Spiele, No. 6, p. 6. The published reply is an abbreviated version of the original answer, which we received from Fürstenberg by personal communication together with some correspondence on this matter with F. Friedel, the Editor-in-Chief of Computerschach und Spiele.

Nunn, J. (1989). Sollen Computer an Schachturnieren teilnehmen? Computerschach und Spiele, No. 5, pp. 5-6. The original is received by intermediary of D.N.L. Levy.

\section{SHOULD COMPUTERS PARTICIPATE IN CHESS TOURNAMENTS?}

\author{
IGM Dr.J.Nunn \\ London / England
}

It has become quite common for computers to take part in chess tournaments, yet many issues concerning man versus machine games have not even been discussed, let alone resolved. The purpose of this short discussion document is to raise some of these issues and offer an admittedly personal opinion on the questions arising.

One may embark on an elaborate discussion of the rules for man versus machine games, but there is a far more basic question which seems to have received strangely little attention: why should computers be allowed to participate at all in tournaments intended for human beings? Perhaps we have become so used to the box in the corner that we have lost sight of what an exceptional situation we are witnessing. In other sports the idea of entering an inanimate object (even with a human operator) into a sports event would be met with incredulity; we do not see fork-lift trucks in the weightlifting. Sports are designed to exercise and test the ability of the human mind/body combination without mechanical aids. Mental qualities as well as physical are important in most sports. Commentators often refer to the mental resilience and determination of sportsmen and women; it is clear that such qualities are important in all sports and not just in chess. In many sports, indeed, concentration is more important than physical attributes; rifle shooting and gliding are two examples. Technology may indeed be important in the training process, but on the day of the event the human participant must perform without any outside help, human, mechanical or electronic. It would be a simple matter to build a machine to "win" in virtually any specific sport, but this would not be a genuine victory because it would be outside the realms of sport.

The introduction of computers into chess events at first seemed a harmless enough innovation; the machines did not play very well and if they caught out some careless fellow, the result was usually laughter. But over the years not only the giant mainframe computers but even the commercially-available dedicated chess machines have gradually become stronger and stronger. Now they have reached the point where they can influence the result of major chess events. In case you do not believe me, I am referring to the British Open Quickplay (i.e., Active Chess) Championships (see this issue, pp. 41-45. - Ed.). A computer took part in this event and made a result corresponding to that of a strong IM player; in particular it defeated the defending titleholder Glenn Flear and drew with Julian Hodgson when the two players were not far off the lead. The computer in question was apparently a prototype for a commercial model which will soon be available. This particular computer would not achieve such a good result in an event played at a normal time limit, but the writing is on the wall; soon commercially-available machines will be capable of winning weekend tournaments. After that it is only a matter of time before the most the organic participants can hope for is the "Best Human Being" prize.

On the other hand, there can be benefits from computer participation in chess events. There is no doubt that computers can generate publicity for a tournament, which may make essential sponsorship easier to find. In some cases, chess-computer manufacturers have put money back into the game by directly sponsoring chess tournaments (Novag and Mephisto spring to mind). Many players, even those who do not like computers, would 
agree that a tournament with a computer is better than no tournament at all. I, for one, would not like to see a blanket ban on computer participation, but there should be restrictions. The Leeds tournament, for example, had always been held before without any computer participation and this year had secured a major new sponsor, the National Westminster Bank. I do not know if the computer entry made a special contribution to the funds of the tournament, but it could not have made a crucial difference. Moreover, this was a major national championship, with substantial prize money, and it seems to me quite wrong that such an event should have its result distorted by the presence of the computer. The final point is that in many tournaments with computer paticipation, one may indicate a $w_{1}$ sh not to be paired against the computer. This was not done at Leeds.

I would therefore like to suggest a set of guidelines for the participation of computers:

1) Computers should be banned from major national events organized by or in conjunction with the British Chess Federation, particularly those with national titles.

2) Computers should be ineligible for cash prizes. Otherwise anybody could turn up with a computer and hope to make an effortless profit. This also avoids possible arguments about whether a computer can win a rating prize, under- 18 prize, etc.

3) If a computer manufacturer or retailer wishes to organize a tournament to demonstrate the abilities of his machines, then he may do so; indeed, he should be encouraged to do so. In this case the entry form should clearly state that in sending in the entry form the player is indicating his willingness to play against the computer.

4) For weekend tournaments I would suggest a special (large) entry fee be introduced for computers (which are in any case much more trouble for the organizers than a human player), and this should be printed on the entry form. Then disgruntled players could at least see that the computer is making a contribution to their tournament. One should not forget that publicity is worth money; a win against a strong player could gives sales of a chess computer a major boost. Organizers should charge a reasonable fee to balance the possible benefits the manufacturer may get out of his participation.

5) Most players dislike playing against computers in tournaments. The reasons for this are not only due to the possible embarrassment of losing. They are also related to the actual circumstances of the game. In particular computer operators often behave incredibly badly. They talk to other people during the game, read newspapers or have a quick snack, in other words, indulge in behaviour which would be totally unacceptable in a human opponent. Then, if their machine should start to win against a strong player, they show undisguised glee, possibly because they are thinking how much the publicity will be worth to them. The normal rules for behaviour at the chess-board should apply to operators, i.e., no talking or distracting behaviour. This will not produce a completely genuine atmosphere, since it is easy to tell that the man on the other side of the board is not completely immersed in the position, but it should help.

These guidelines should be revised to take into account new trends in the development of chess computers, but I believe it is essential to think now about how the participation of computers can be regulated so as not to destroy the enjoyment that thousands of players obtain from playing in tournaments, while not depriving chess of any benefits which may be derived from the computer. 